\title{
Development of a dendrimer PAMAM-based gold biochip for rapid and sensitive detection of endogenous IFN- $\gamma$ and anti-IFN- $\gamma$ IgG in patients with hemophagocytic lymphohistiocytosis
}

\author{
YI-XIN DU ${ }^{1 *}$, LEI YE ${ }^{2 *}$, ZI-JIAN SONG ${ }^{3 *}$, HUI LV $^{4}$, QIAN LIU ${ }^{5}$, SONG-GUO LI ${ }^{5}$, \\ SHENG-SHENG LIU ${ }^{5}$, JIAN HONG ${ }^{6}$, YI GAO ${ }^{5}$, MARION E. SCHNEIDER ${ }^{1}$ and WEI-DONG DU ${ }^{5}$
}

${ }^{1}$ Division of Experimental Anesthesiology, University Hospital Ulm, D-89081 Ulm, Germany; ${ }^{2}$ Department of Neurosurgery, The First Affiliated Hospital of Anhui Medical University, Hefei, Anhui 230022; ${ }^{3}$ Department of Orthopaedics, Xuzhou No. 1 People's Hospital, Xuzhou, Jiangsu 221002; ${ }^{4}$ Department of Biology, School of Life Sciences;

${ }^{5}$ Department of Pathology, Anhui Medical University, Hefei, Anhui 230032; ${ }^{6}$ Department of Haematology,

The First Affiliated Hospital of Anhui Medical University, Hefei, Anhui 230022, P.R. China

Received March 10, 2020; Accepted September 11, 2020

DOI: $10.3892 / \mathrm{mmr} .2020 .11605$

\begin{abstract}
Hemophagocytic lymphohistiocytosis (HLH) is a rare but severe disease characterized by immune hyperactivation and cytokine storm. Given the high mortality rate of $\mathrm{HLH}$, there is a need for more effective diagnostic tools and treatments. The present study developed a dendrimer-based protein biochip for rapid, sensitive and simultaneous detection of serum interferon (IFN) $-\gamma$ and endogenous anti-IFN- $\gamma$ antibody $(\mathrm{Ab})$ in patients with HLH. A gold biochip was modified with 1, 4-phenylene diisothiocyanate (PDITC), polyamidoamine (PAMAM) or PDITC-activated PAMAM. The optimal immobilization concentration for $\mathrm{Ab}$ capture and the reaction concentration for detecting $\mathrm{Ab}$ on the PDITC-activated PAMAM-modified biochip were 6.25 and $3.12 \mu \mathrm{g} / \mathrm{ml}$, respectively; the limit of detection of IFN- $\gamma$ protein was $50 \mathrm{pg} / \mathrm{ml}$. The efficiency of the protein-probed biochip in detecting IFN- $\gamma$ and anti-IFN- $\gamma \mathrm{Ab}$ in serum samples from 77 patients with HLH was evaluated; the positive rates for IFN- $\gamma$ and anti-IFN- $\gamma$ IgG Ab were $63.6 \%$ (49/77) and $61.0 \%$ (47/77), respectively. The present results demonstrated that the PDITC-activated PAMAM-modified biochip might
\end{abstract}

Correspondence to: Professor Wei-Dong Du, Department of Pathology, Anhui Medical University, 81 Meishan Road, Shushan, Hefei, Anhui 230032, P.R. China

E-mail: weidong.du@ahmu.edu.cn

Professor Marion E. Schneider, Division of Experimental Anesthesiology, University Hospital Ulm, Albert-Einstein-Allee 23, D-89081 Ulm, Germany

E-mail: marion.schneider@uniklinik-ulm.de

*Contributed equally

Key words: hemophagocytic lymphohistiocytosis, dendrimer, polyamidoamine, protein biochip, interferon- $\gamma$ be a sensitive tool for the specific detection of IFN- $\gamma$ and anti-IFN- $\gamma$ Ab in serum, and might have clinical applicability for the diagnosis of HLH.

\section{Introduction}

Hemophagocytic lymphohistiocytosis (HLH) is a rare but severe disease characterized by hyperactivation of $\mathrm{T}$ lymphocytes and macrophages, and a potentially life-threatening cytokine storm $(1,2)$. Although there have been improvements in the diagnosis and treatment of HLH, the mortality rate remains high, with a 5-year overall survival of 54\% reported by the Histiocyte Society in 2011 (3). Therefore, more effective tools are required for early HLH diagnosis so that treatment can be initiated in a timely manner and patient outcomes improved.

The pathogenesis of HLH is complex $(4,5)$. Infection is one of the most common triggers, but symptoms caused by HLH are difficult to differentiate from those associated with severe infection (6). Serum expression levels of various cytokines including soluble interleukin-2 receptor (7) and plasma ferritin (8) have been used to distinguish HLH from other syndromes. However, as the expression levels of these cytokines can increase slowly over the course of pathogenesis, they are not useful for evaluating the acute phase of HLH (6). Interferon (IFN) $-\gamma$ is a potential biomarker for HLH pathogenesis, as serum concentrations increase rapidly at disease onset and decrease upon treatment (9). It has previously been demonstrated in mouse models that neutralizing anti-IFN- $\gamma$ antibody $(\mathrm{Ab})$ may be an effective therapy for HLH $(10,11)$. However, only a few studies have investigated anti-cytokine antibodies produced by patients with $\operatorname{HLH}(12,13)$.

Biochip technology has the advantages of possessing high throughput, sensitive and specific, and has broad biological applications, for example, in genomic library construction or oligonucleotide and protein detection. Biochip surfaces are typically pretreated with different chemicals to produce a self-assembled monolayer with varying sensitivity and 
capacity for binding biomolecules (14-16). Polyamidoamine (PAMAM) dendrimer has been used as a chemical linker that enhances signals in fluorophore-based (17) or electrical (18) biosensors. PAMAM modification of a gold substrate was speculated to enhance the sensitivity of biochips for protein detection. Although a variety of assays have been used to detect IFN- $\gamma$ in serum $(19,20)$, biochips are highly selective and require only small amounts of sample, which is useful in clinical situations where blood sample volume is very limited or where repeated sampling can put patients at risk.

The present study developed a strategy for PAMAM-based chemical modification on a gold biochip, and evaluated the performance of the modified biochip in the detection of IFN- $\gamma$ protein and anti-IFN- $\gamma \mathrm{Ab}$ in serum samples from patients with HLH.

\section{Materials and methods}

Study population. Serum samples $(3 \mathrm{ml})$ from patients with HLH ( $=77 ; 42$ male patients and 35 female patients; age, 23.2 \pm 23.9 years) were collected from Anhui Medical University (Hefei, China) between November 2012 and September 2014. HLH diagnosis was based on the guidelines of the Histiocyte Society (4). Serum samples from four healthy individuals (two men and two women; age, 28.5 \pm 12.1 years) also collected between November 2012 and September 2014 were used as controls. Written informed consent was obtained from all study participants, and the study protocol was approved by the Institutional Ethics Committee of Anhui Medical University. All procedures were performed in accordance with the ethical standards of the institutional and/or national research committees and with the 1964 Helsinki declaration and its later amendments.

Reagents and equipment. All chemicals were of reagent grade and used as received unless otherwise indicated. PBS (0.01 M, pH 7.4), 1, 4-phenylene diisothiocyanate (PDITC), PAMAM G4.0, dimethylformamide (DMF), acetone and bovine serum albumin (BSA) were purchased from Sigma-Aldrich (Merck KGaA). Absolute ethanol was from Sangon Biotech Co., Ltd. Rabbit anti-human IFN- $\gamma$ polyclonal (p)Ab (cat. no. ab9657), mouse anti-human IFN- $\gamma$ monoclonal (m) $\mathrm{Ab}$ (cat. no. ab9658) and recombinant human IFN- $\gamma$ protein (cat. no. ab119140) were from Abcam. Cy3-conjugated anti-human IgG (cat. no. D110142) and Cy3-conjugated anti-mouse IgG (cat. no. D110088) were from Sangon Biotech Co., Ltd.

Biochips were generously supplied by the Interactiva Division of Thermo-Hybaid. The dimensions of the biochip were previously described (21). Glass slides $(75 \times 25 \mathrm{~mm})$ were coated with gold film $(0.1 \mu \mathrm{m})$ and a layer of Teflon $(50 \mu \mathrm{m})$ was added that divided the gold surface into an $8 \times 24$ matrix spot layout; the diameter of each spot was $1.5 \mathrm{~mm}$. The chip was scanned using a LuxScan 10K-A microarray scanner (CapitalBio Technology Inc.). Atomic force microscopy (AFM) was performed using a Dimension atomic force microscope (Digital Instruments, Inc.) or an Innova microscope (Veeco Instruments Inc.). Attenuated total reflectance Fourier transform infrared spectrometry (ATR-FTIR) was performed using a Nicolet 8700 instrument (Thermo Fisher Scientific, Inc.).
Chemical modification and characterization of the gold biochip. A workflow for chemical modification and assay evaluation in detection of IFN- $\gamma$ in serum from patients with HLH with the biochip is presented in Figs. 1 and 2. The gold slides were cleaned in a 5:1:1 (v/v/v) $\mathrm{H}_{2} \mathrm{O}: \mathrm{H}_{2} \mathrm{O}_{2}: \mathrm{NH}_{3} \bullet \mathrm{H}_{2} \mathrm{O}$ solution at $82^{\circ} \mathrm{C}$ for $5 \mathrm{~min}$, then rinsed with sterile water followed by anhydrous ethanol and dried under a flow of nitrogen (5 1/min). PDITC was dissolved in DMF solution to a final concentration of $10 \mathrm{mM}$. PAMAM G4.0 was dissolved in PBS to a final concentration of $0.01 \mathrm{mM}$. The cleaned slides were incubated in PDITC solution for $2 \mathrm{~h}$ in the dark with gentle shaking; they were then washed 3 times for 3 min each with DMF, followed by ethanol and dried under a nitrogen flow as aforementioned. The PDITC-modified slides were incubated in PAMAM solution $(0.01 \mathrm{mM})$ for $8 \mathrm{~h}$ in the dark with vigorous shaking. The slides were washed 3 times for $3 \mathrm{~min}$ each in ethanol followed by PBS-Tween (PBST; $0.1 \% \mathrm{v} / \mathrm{v}$ Tween-20) and dried under a nitrogen flow. For PAMAM activation by PDITC, the slides were incubated in PDITC solution for $2 \mathrm{~h}$ in the dark with shaking, washed with 3 times for 3 min each in DMF solution followed by absolute ethanol and dried under a nitrogen flow. All the steps were performed at room temperature $\left(\mathrm{RT} ; 24^{\circ} \mathrm{C}\right)$. The ready-to-use biochips were stored at $4^{\circ} \mathrm{C}$ until further use.

Chemical characterization of the PDITC-activated PAMAM-modified biochip was performed by AFM and ATR-FTIR. Scan rates ranged from 1-5 Hz, and scan size was set according to a $5-\mu \mathrm{m}$ engagement of the cantilever. The instrument was operated in tapping mode to obtain height images that were processed using Nanoscope VII software (Version 6.13; Veeco Instruments, Inc.). The images were flattened to remove scan lines, and the height scale was set to $20 \mathrm{~nm}$. Feedback control was modulated in real time as images were being generated. Integral and proportional gains were set between 2.0 and 0.5. ATR-FTIR spectra were obtained in the $674-3,999 \mathrm{~cm}^{-1}$ spectral range over 128 scans at an atomic resolution of $8 \mathrm{~cm}^{-1}$.

Comparative analysis of immobilization efficiency on PDITC, PAMAM and PDITC-activated PAMAM biochips. Serial two-fold dilutions of human $\operatorname{IgG}$ were prepared to test the protein-binding efficiency of the chemically modified biochips. IgG solutions with concentrations ranging between 0.001 and $10 \mu \mathrm{g} / \mathrm{ml}$ were immobilized on PDITC, PAMAM and PDITC-activated PAMAM biochips for $2 \mathrm{~h}$ at RT, then washed three times with PBST and dried under a nitrogen flow. The biochips were incubated with $2.5 \mu \mathrm{g} / \mathrm{ml} \mathrm{Cy3-conjugated}$ anti-human IgG at RT for $30 \mathrm{~min}$ in the dark. After washing with PBS-0.1\% Tween-20 buffer and drying with a nitrogen flow, the fluorescence intensity of each spot on the biochips was scanned and measured by the microarray scanner and semi-quantified using ImageJ software (Version 1.52t; National Institutes of Health).

Quantification of immobilized anti-IFN- $\gamma$ pAb and detected anti-IFN- $\gamma$ mAb on biochips. To optimize the concentration of anti-human IFN- $\gamma$ pAb (capture $\mathrm{Ab}$ ) on the biochips, serial two-fold dilutions of rabbit anti-human IFN- $\gamma$ pAb in PBST-BSA buffer [0.1\% Tween-20 (v/v), 0.1\% BSA (wt/v), $\mathrm{pH} 7.4]$ with various concentrations ranging between 0.000006 

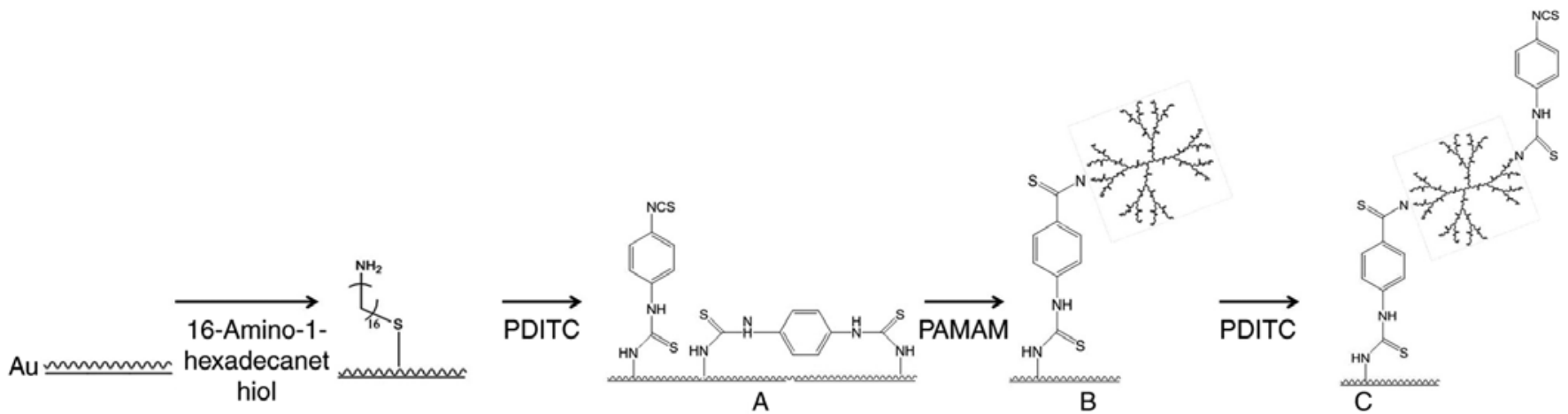

Figure 1. Schematic representation of surface modifications. (A) PDITC biochip. (B) PAMAM biochip. (C) PDITC-activated PAMAM biochip. PDITC, 1, 4-phenylene diisothiocyanate; PAMAM, polyamidoamine.

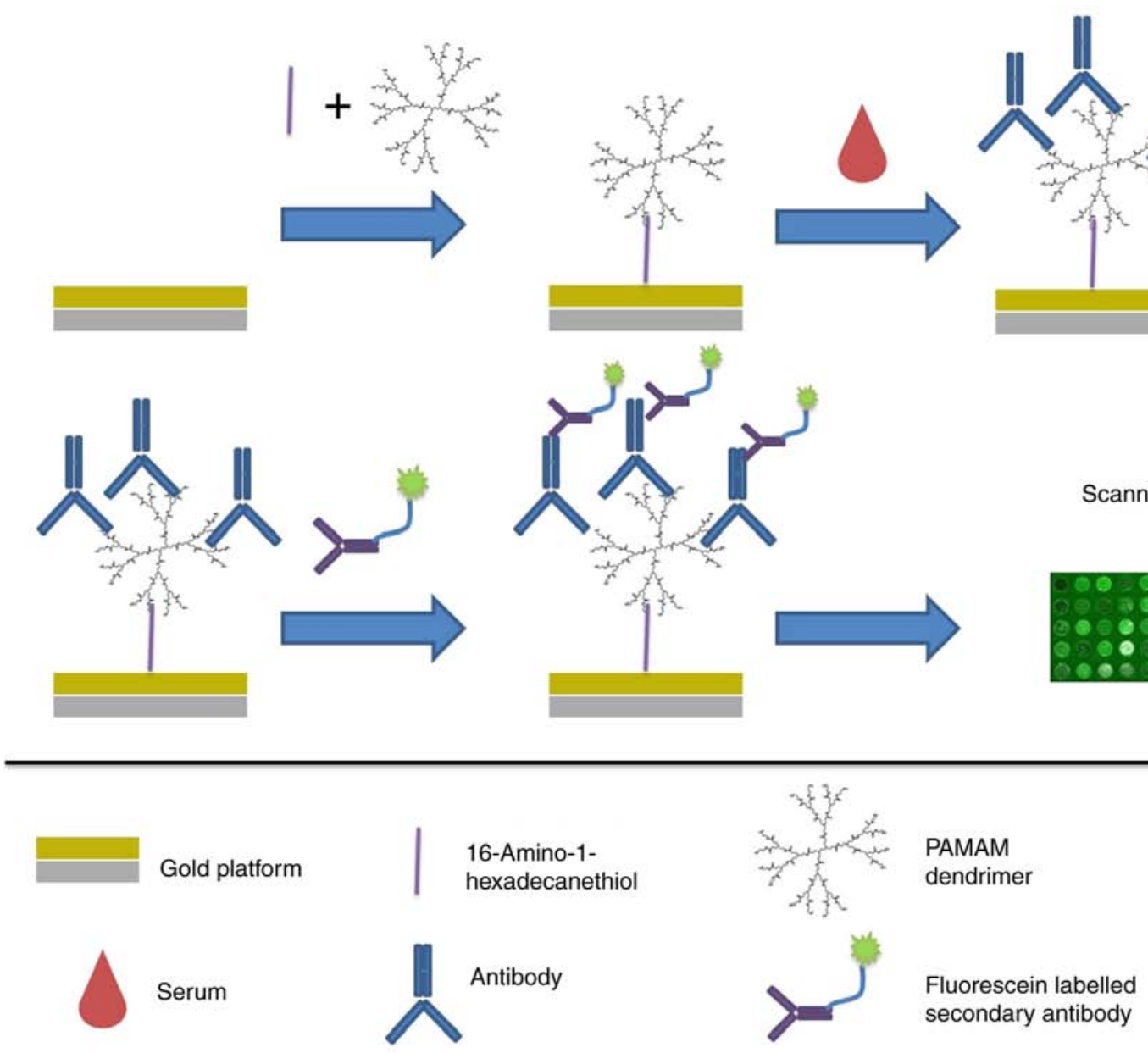

Figure 2. Schematic of the workflow for detection of IFN- $\gamma$ in the serum of patients with hemophagocytic lymphohistiocytosis with the biochip. PAMAM, polyamidoamine.

and $25 \mu \mathrm{g} / \mathrm{ml}$ were immobilized onto the biochips at RT for $2 \mathrm{~h}$. The biochips were washed three times with PBST, dried under a nitrogen flow, then incubated with $10 \mu \mathrm{g} / \mathrm{ml}$ recombinant human IFN- $\gamma$ protein and $10 \mu \mathrm{g} / \mathrm{ml}$ mouse anti-human IFN- $\gamma$ $\mathrm{mAb}$ (detection $\mathrm{Ab}$ ) at RT for $1 \mathrm{~h}$, followed by $2.5 \mu \mathrm{g} / \mathrm{ml}$ of Cy3-conjugated anti-mouse IgG at RT for $30 \mathrm{~min}$ in the dark. After washing and drying as aforementioned, the fluorescence intensity of each spot on the biochips was semi-quantified using ImageJ software.
To determine the optimal reaction concentration of detection $\mathrm{Ab}$, serial two-fold dilutions of mouse anti-human IFN- $\gamma$ $\mathrm{mAb}$ were prepared in PBST-BSA buffer $(\mathrm{pH} 7.4)$ with concentrations ranging between 0.000006 and $25 \mu \mathrm{g} / \mathrm{ml}$. The reaction steps were the same as those used for the aforementioned capture Ab. Briefly, $6.25 \mu \mathrm{g} / \mathrm{ml}$ rabbit anti-human IFN- $\gamma$ pAb was immobilized on the chemically modified biochips at RT for $2 \mathrm{~h}$; subsequently, $10 \mu \mathrm{g} / \mathrm{ml}$ recombinant human IFN- $\gamma$ protein was applied to each spot at RT for $1 \mathrm{~h}$, followed by incubation 
of the biochips with serial five-fold diluted mouse anti-human IFN- $\gamma$ mAb solution at RT for $1 \mathrm{~h}$. Finally, the biochips were incubated with $2.5 \mu \mathrm{g} / \mathrm{ml} \mathrm{Cy3-conjugated} \mathrm{anti-mouse} \mathrm{IgG} \mathrm{Ab}$ at RT for $30 \mathrm{~min}$ in the dark. After washing and drying as aforementioned, the fluorescence intensity of each spot on the biochip was semi-quantified using ImageJ software.

Determination of the limit of detection (LOD) for IFN- $\gamma$. The LOD of IFN- $\gamma$ protein by the PDITC-activated PAMAM-modified biochip was determined. Serial five-fold dilutions of IFN- $\gamma$ protein in PBST-BSA buffer $(\mathrm{pH} 7.4)$ were prepared with concentrations ranging between 0.00001 and $100 \mu \mathrm{g} / \mathrm{ml}$. Rabbit anti-human IFN- $\gamma$ pAb $(6.25 \mu \mathrm{g} / \mathrm{ml})$ was immobilized on the biochip at RT for $2 \mathrm{~h}$. Subsequently, the biochip was incubated with the serial two-fold diluted IFN- $\gamma$ protein solution at RT for $1 \mathrm{~h}$, along with $3.12 \mu \mathrm{g} / \mathrm{ml}$ mouse anti-human IFN- $\gamma$ mAb at RT for $1 \mathrm{~h}$, and $2.5 \mu \mathrm{g} / \mathrm{ml}$ Cy3-conjugated anti-mouse IgG Ab at RT for $30 \mathrm{~min}$ in the dark. After washing and drying as aforementioned, the fluorescence intensity of each reaction spot on the biochip was semi-quantified using ImageJ software.

On-chip assay for serum IFN- $\gamma$ and anti-human IFN- $\gamma$ Ab detection in patients with HLH. Ready-to-use probe biochips were produced by immobilization of $6.25 \mu \mathrm{g} / \mathrm{ml}$ anti-human IFN $-\gamma$ pAb at RT for $2 \mathrm{~h}$. A total of 77 serum samples from patients with HLH and four samples from healthy subjects (negative control) were diluted 1:40 with $0.01 \mathrm{mM}$ PBST-BSA ( $\mathrm{pH}$ 7.4). The biochip was incubated with the samples at RT for $1 \mathrm{~h}$, followed by $3.12 \mu \mathrm{g} / \mathrm{ml}$ mouse anti-human IFN- $\gamma$ $\mathrm{mAb}$ at RT for $1 \mathrm{~h}$ and $2.5 \mu \mathrm{g} / \mathrm{ml} \mathrm{Cy3-conjugated} \mathrm{anti-mouse}$ IgG at RT for $30 \mathrm{~min}$ in the dark. After washing and drying as aforementioned, the fluorescence intensity of each spot on the biochip was semi-quantified using ImageJ software. PBST-BSA buffer was used as the blank control.

Immunological blocking assays of IFN- $\gamma$ and anti-human $I F N-\gamma A b$. Before blocking assay of serum samples from patients with HLH on biochips, four samples from the patients with HLH that were previously tested to be positive were randomly chosen. These serum samples were incubated in vials at RT for $1 \mathrm{~h}$ with anti-human IFN- $\gamma \mathrm{mAb}$ and recombinant human IFN- $\gamma$ protein, respectively, at ten-fold diluted concentrations ranging between 0.01 and $10 \mu \mathrm{g} / \mathrm{ml}$ The same samples without pretreatment and four serum samples from healthy individuals were used as positive and negative controls, respectively. Anti-human IFN- $\gamma$ pAb $(6.25 \mu \mathrm{g} / \mathrm{ml})$ was immobilized onto the biochip at RT for $1 \mathrm{~h}$. Subsequently, the biochip was incubated with the pretreated or untreated serum samples and $10 \mu \mathrm{g} / \mathrm{ml}$ mouse anti-human IFN- $\gamma$ mAb at RT for $1 \mathrm{~h}$, followed by $2.5 \mu \mathrm{g} / \mathrm{ml} \mathrm{Cy} 3$-conjugated anti-mouse $\mathrm{IgG}$ at RT for $30 \mathrm{~min}$ in the dark. The fluorescence intensity of each spot was semi-quantified using ImageJ software.

Statistical analysis. SPSS software (v19.0; IBM Corp.) was used for statistical analysis. All numerical data were presented as the mean \pm SD. Correlations between variables were calculated using Pearson's correlation analysis. $\mathrm{P}<0.05$ was considered to indicate a statistically significant difference.

\section{Results}

Characterization of activated PAMAM-modified biochip. The efficiency for biocompatibility of anti-human IgG immobilization was visually superior for the PDITC-activated PAMAM biochip compared with the PDITC and PAMAM biochips (Fig. S1). Activated PAMAM was crosslinked between biochip substrate and probe proteins. A chemical characterization of PAMAM was performed via ATR-FTIR. The major absorbance of functional groups in PAMAM were $834 \mathrm{~cm}^{-1}(\mathrm{C}-\mathrm{H}$ out-of-plane bending vibration of the benzene ring), $1,183 \mathrm{~cm}^{-1}$ (C-N stretching vibration), 1,092-1,229 $\mathrm{cm}^{-1}$ (C=S stretching vibration of the thiourea group), $1,619-1,784 \mathrm{~cm}^{-1}$ (C-C framework vibration of the benzene ring and $\mathrm{N}-\mathrm{H}$ stretching vibration of the secondary amino group), 2,102-2,286 $\mathrm{cm}^{-1}$ (broad peak corresponding to $-\mathrm{N}=\mathrm{C}=\mathrm{S}$ moiety vibration), $3,025 \mathrm{~cm}^{-1}$ (C-C stretching vibration of the hexadecane group and $\mathrm{C}-\mathrm{H}$ stretching vibration of the benzene ring) and $3,247 \mathrm{~cm}^{-1}(\mathrm{~N}-\mathrm{H}$ stretching vibration of the primary amino group) (Fig. 3A). Images of 3-dimensional AFM of a PDITC-activated PAMAM-modified biochip and a cleaned biochip are shown in Fig. 3B and C. The peak height was higher on the PAMAM-modified gold surface than on the non-modified surface, which indicated a strong anchoring of the protein. Height measurements determined by AFM reflected the binding of chemical components as well as their interaction with proteins; the peak height was $>20 \mathrm{~nm}$ on the PAMAM-modified surface compared with 0-3 nm on the cleaned surface, which indicated that the functional groups were covalently bound.

Optimization of capture and detection Ab concentrations. The concentrations of anti-human IFN- $\gamma \mathrm{pAb}$ and anti-human IFN- $\gamma$ mAb immobilized on the PDITC-activated PAMAM-modified biochip were optimized. Fluorescence signal intensity increased with anti-human IFN- $\gamma$ pAb concentration, but reached a plateau at $6.25 \mu \mathrm{g} / \mathrm{ml}$, which indicated saturation of the biochip surface with anti-IFN- $\gamma$ pAb. Thus, the optimal concentration for immobilization of captured $\mathrm{Ab}$ was determined as $6.25 \mu \mathrm{g} / \mathrm{ml}$ (Fig. S2). Similarly, the optimal concentration for the detection $\mathrm{Ab}$ was determined as $3.12 \mu \mathrm{g} / \mathrm{ml}$ (Fig. S3).

LOD of IFN- $\gamma$ protein by PDITC-activated PAMAM-modified biochip. The LOD of IFN- $\gamma$ protein was subsequently evaluated via the PDITC-activated PAMAM-modified biochip; the cut-off for a positive signal was a fluorescence intensity $>2$ times the mean value and 2 standard deviations above the background value. The defining method used to determine the cutoff value was that which is usually clinically applied. According to these criteria, the LOD of IFN- $\gamma$ protein by the biochip was determined as $50 \mathrm{pg} / \mathrm{ml}$ (Fig. 4).

Detection of IFN- $\gamma$ and anti-human IFN- $\gamma$ Ab in HLH serum samples by the PDITC-activated PAMAM-modified biochip and immunological blocking assays. The clinical applicability of the PDITC-activated PAMAM-modified biochip was evaluated using serum samples from 77 patients with HLH (Fig. 5). The positive detection rates for IFN- $\gamma$ and anti-IFN- $\gamma$ IgG Ab were $63.6 \%$ (49/77) and 61.0\% (47/77), respectively. Simultaneous detection of IFN- $\gamma$ and anti-human IFN- $\gamma$ IgG Ab expression 


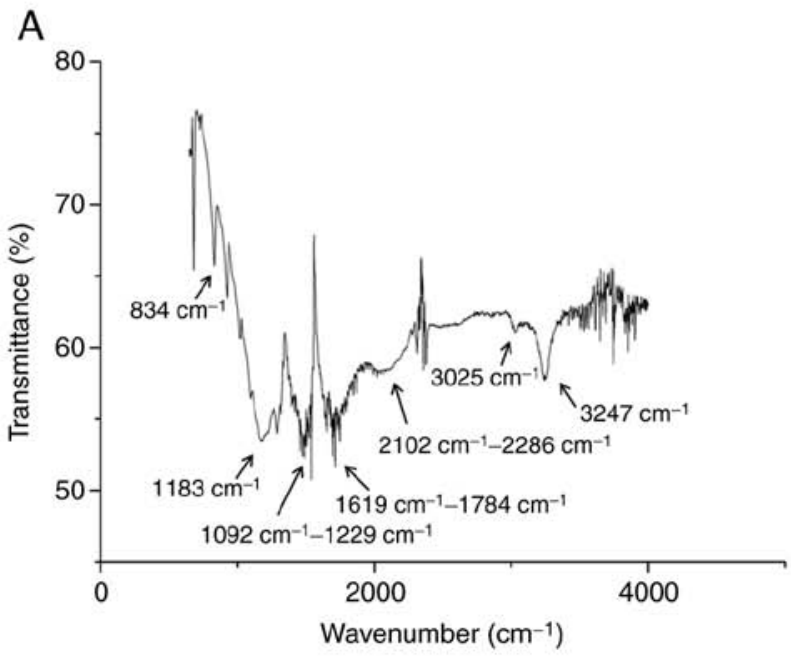

B
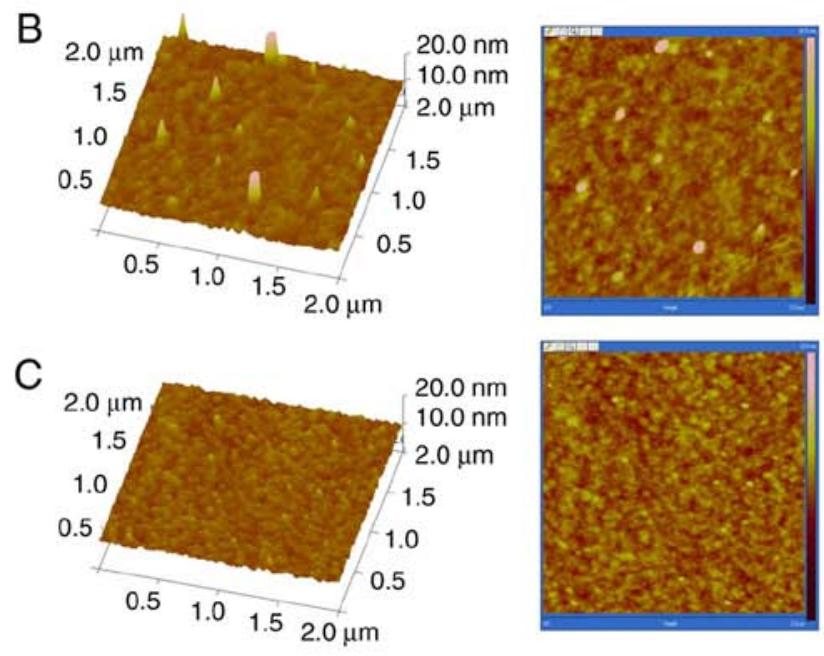

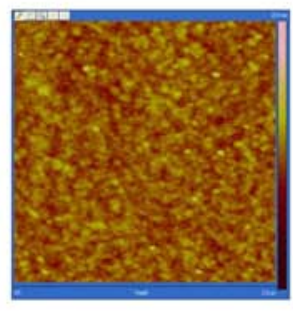

Figure 3. Characterization of the PDITC-activated PAMAM-modified biochip by ATR-FTIR and AFM. PAMAM-modified biochip surface was characterized by (A) ATR-FTIR and (B) AFM. (C) Unmodified biochip surface characterization was performed by AFM. PDITC, 1, 4-phenylene diisothiocyanate; PAMAM, polyamidoamine; ATR-FTIR, attenuated total reflectance Fourier transform infrared spectrometry; AFM, atomic force microscopy.

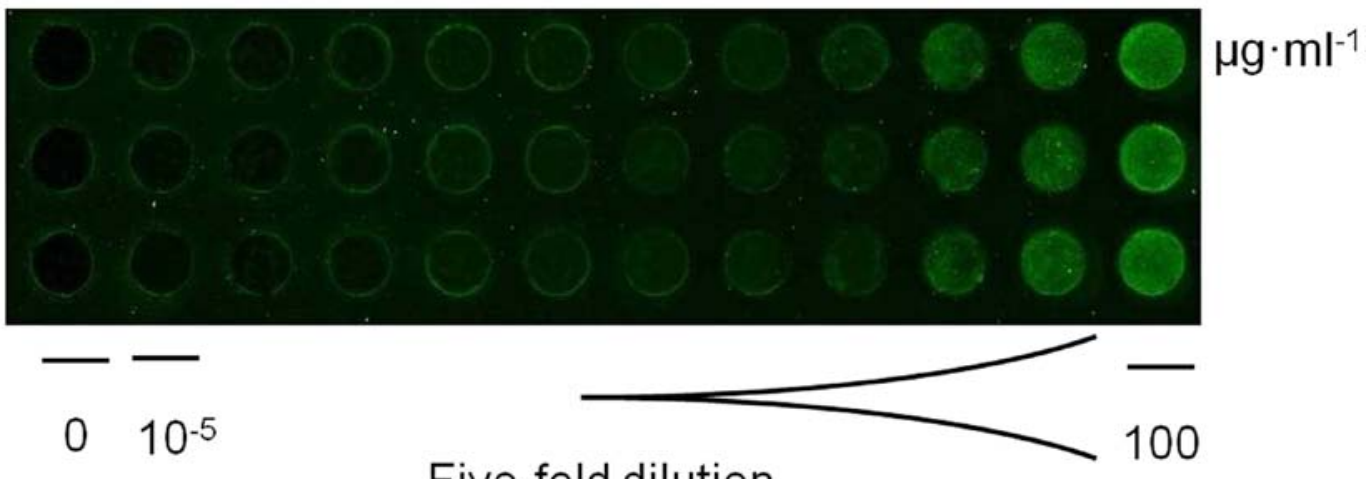

Five-fold dilution

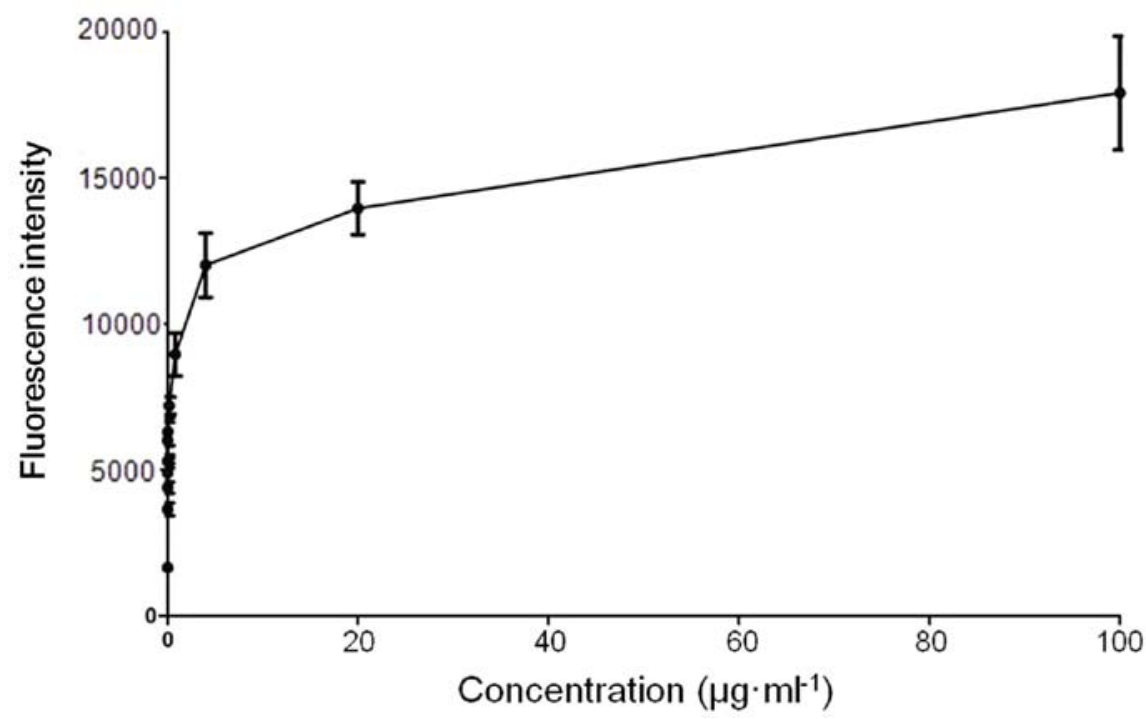

Figure 4. Limit of detection of anti-interferon $-\gamma$ antibody by the biochip. The green fluorescence represents stronger binding strength. The three rows represent three repeats. The data are presented as the mean $\pm S D(n=3)$.

levels in serum samples using the biochip revealed no correlation $\left(\mathrm{R}^{2}=-0.218 ; \mathrm{P}>0.05\right.$, Pearson's analysis; data not shown).
Immunological blocking assays were performed to measure the specificity of the biochip. IFN- $\gamma$ and anti-human 


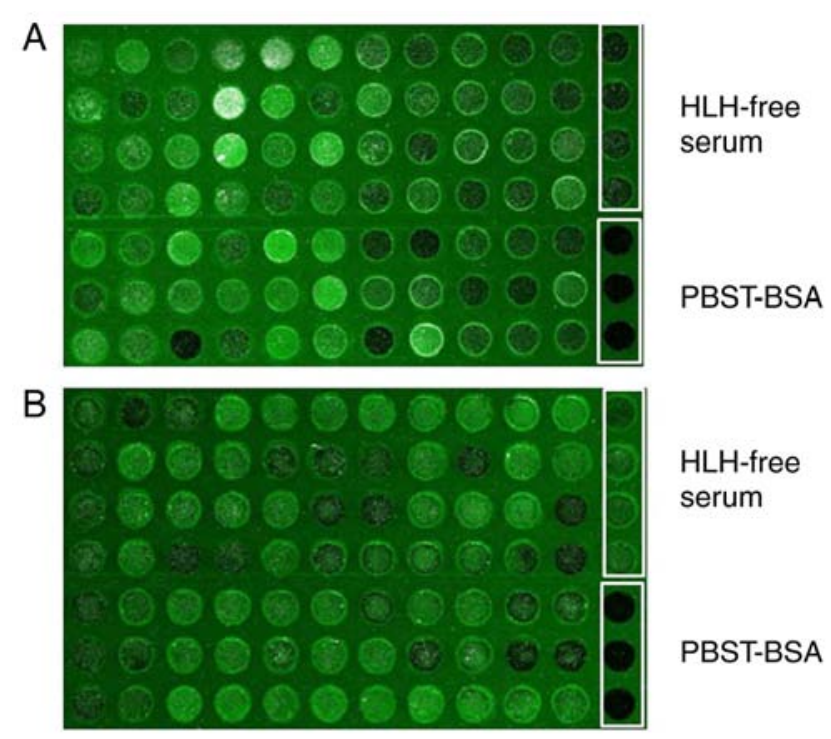

Figure 5. IFN- $\gamma$ and anti-human IFN- $\gamma$ Ab expression levels in the serum of patients with HLH. (A) IFN- $\gamma$ and (B) anti-human IFN- $\gamma$ Ab in serum samples from patients with HLH $(n=77)$ and HLH-free individuals $(n=4)$ were detected on the 1,4-phenylene diisothiocyanate-activated polyamidoamine-modified biochip. Ab, antibody; HLH, hemophagocytic lymphohistiocytosis; IFN- $\gamma$, interferon $\gamma$.

IFN- $\gamma$ IgG Ab in serum samples were completely neutralized by adding blocking molecules at increasing concentrations ranging from 0.00005 to $0.05 \mu \mathrm{g} / \mathrm{ml}$, as evidenced by the dose-dependent decrease in the fluorescent signal (Fig. 6). The present results indicated that the biochip did not detect any other serum factors besides IFN- $\gamma$ protein or anti-human IFN- $\gamma \mathrm{Ab}$.

\section{Discussion}

The specificity and sensitivity of target molecule detection are critical considerations in biochip fabrication. PAMAM is a type of cationic and branched dendrimer that has numerous applications; the abundance of amino groups at the outer ends of the PAMAM molecule provides multiple potential sites for protein loading and signal amplification in protein detection $(22,23)$.

The present study used three strategies to chemically modify the gold surface of a biochip, namely PDITC modification, PAMAM modification and PDITC-activated PAMAM modification. Although PAMAM has multiple surface amino moieties, these cannot be directly conjugated with proteins, and PDITC was therefore used for their complete activation. The present results demonstrated that the PDITC-activated PAMAM-modified biochip revealed stronger protein immobilization than those modified by either PIDTC or PAMAM alone, confirming that activation of amino groups enhances protein conjugation capacity on the PDITC-activated PAMAM-modified biochip (24). PDITC is a homobifunctional chemical that can engage in interactions via amino moieties at both of its termini, leaving few active isothiocyanate terminals on PDITC biochips (25). The present study revealed that PDITC-activated PAMAM biochips exhibited a signal 
A

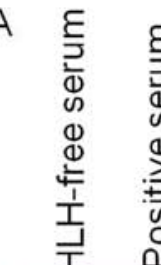

B

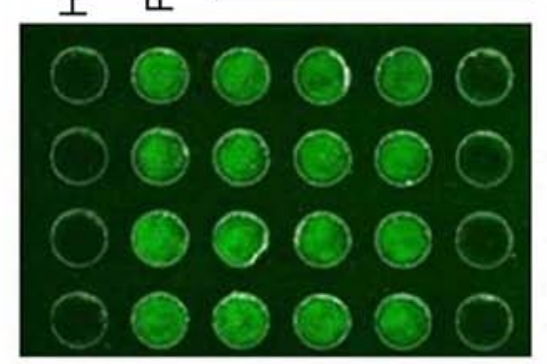

Sample 1

Sample 2

Sample 3

Sample 4

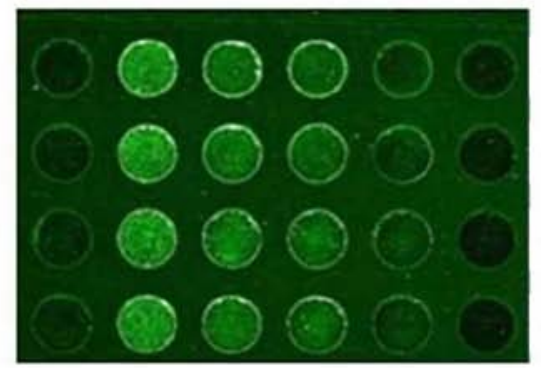

Sample 1

Sample 2

Sample 3

Sample 4

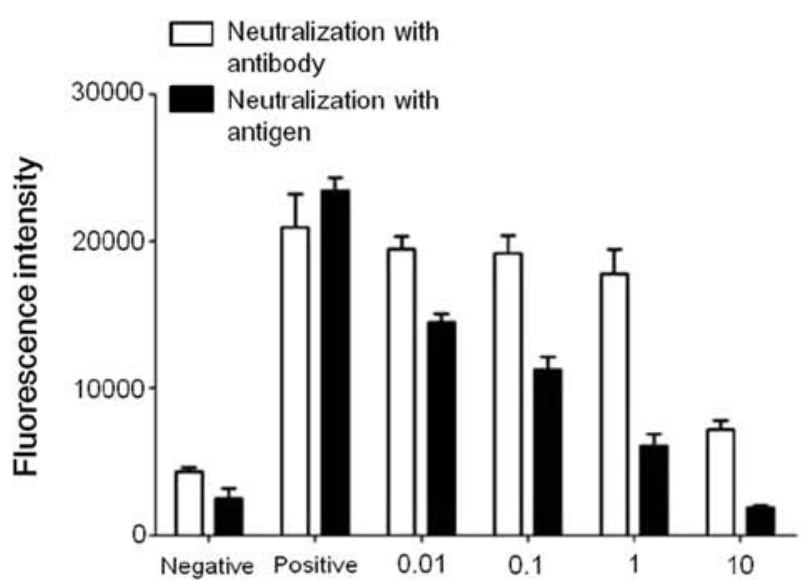

Neutralization concentration $\left(\mu \mathrm{g} \cdot \mathrm{ml}^{-1}\right)$

Figure 6. Immunological blocking assays (neutralization tests) for specificity determination by the biochip in measurement of IFN- $\gamma$ protein and anti-human IFN- $\gamma$ Ab. (A) Positive reactions for IFN- $\gamma$ (upper) or anti-human IFN- $\gamma$ Ab (lower) in serum samples from randomly selected patients with HLH (n=4) were blocked by pretreatment with anti-human IFN- $\gamma$ Ab and IFN- $\gamma$ protein in vials. The serum samples was incubated with serial ten-fold diluted anti-human IFN- $\gamma$ mAb and recombinant human IFN- $\gamma$ protein, respectively, with concentrations ranging between 0.01 and $10 \mu \mathrm{g} / \mathrm{ml}$. (B) Densitometric semi-quantitative analysis from the fluorescence assay shown as a bar chart. The data are presented as the mean \pm SD (n=4). Ab, antibody; HLH, hemophagocytic lymphohistiocytosis; IFN- $\gamma$, interferon $\gamma$.

amplification effect in interactions with proteins. In the present study, the total bond length of PDITC ranged from $1,012 / 10^{-12}$ to $1,032 / 10^{-12} \mathrm{~m}\left[\mathrm{C}-\mathrm{N}, 148 / 10^{-12} \mathrm{~m} ; \mathrm{C}=\mathrm{N}\right.$, $135 / 10^{-12} \mathrm{~m} ; \mathrm{C}=\mathrm{S}, 156 / 10^{-12} \mathrm{~m} ; \mathrm{C}_{6} \mathrm{H}_{6}$ (diameter of benzene ring), $134-154 / 10^{-12} \mathrm{~m}$, which are much shorter than the distance between the amino moieties at its termini, enabling the PDITC-activated PAMAM biochip to bind proteins more efficiently. Thus, it was inferred that bioconjugation may occur between the isothiocyanate terminal of PDITC and the amino terminals of proteins. In the present study, the LOD of IFN- $\gamma$ protein by the biochip was determined as $50 \mathrm{pg} / \mathrm{ml}$. The optimal immobilization concentration for the capture $\mathrm{Ab}$ was extremely low $(6.25 \mu \mathrm{g} / \mathrm{ml})$, which indicated that this surface may hold a higher sensitivity in measuring proteins. A previous study reported serum IFN- $\gamma$ concentration in the order of $\mathrm{ng} / \mathrm{ml}$ in patients with HLH (6). In a previous study, the LOD for a target protein using the biochip with a single-branched chemical modification was $0.78 \mu \mathrm{g} / \mathrm{ml}$ (26). Notably, the novel multi-branched PAMAM biochip in the present study seems to have greater protein-loading and signal amplification capacities, which increases the sensitivity of protein detection.

The diagnostic criteria for HLH are mainly based on clinical signs and laboratory findings. However, due to the relatively non-specific nature of symptoms and their extensive overlap with those of other illnesses, HLH is often misdiagnosed (4). Conventional diagnostic tests have certain disadvantages, for example, the diagnostic accuracy of serum ferritin concentration is limited to the range of 500-10,000 $\mu \mathrm{g} / 1$, whereas ferritin expression levels can reach $10,000 \mu \mathrm{g} / 1$ at the early stage of HLH. Furthermore, serum ferritin expression levels decrease slowly in response to treatment, undermining its utility as a biomarker for evaluating therapeutic efficacy (27). By contrast, the expression levels of IFN- $\gamma$ produced by $\mathrm{CD}^{+} \mathrm{T}$-cells increase soon after $\mathrm{HLH}$ onset and rapidly decrease from $>5,000 \mathrm{pg} / \mathrm{ml}$ to normal levels within $48 \mathrm{~h}$ after treatment (8). In addition, overproduction of endogenous IFN- $\gamma$ may contribute to liver impairment and coagulation disease (28), making IFN- $\gamma$ a potential biomarker for monitoring HLH progression. According to the manufacturer's information, the detectable concentration limit of the biochips is comparable with that of traditional ELISA [e.g. $50 \mathrm{pg} / \mathrm{ml} \mathrm{vs.} 15 \mathrm{pg} / \mathrm{ml}$ with the Human Interferon- $\gamma$ ELISA Kit (cat. no. ab100573; Abcam)]. Binding affinity of IFN- $\gamma$ protein was evaluated by the biochip in comparison with conventional assay techniques $(19,20)$ (Table I). However, biochips have the advantages of high throughput, concurrent measurement of multiple serum factors and requirement of a small volume of biological sample.

Autoantibodies, antigens and inflammatory mediators can trigger inflammation $(29,30)$. Although circulating autoantibodies have been detected in patients with HLH $(29,31)$, to the best of our knowledge, there have been no reports of endogenous anti-IFN- $\gamma$ IgG production in the context of HLH pathogenesis. In preclinical trials, neutralizing 
anti-IFN- $\gamma$ Ab was revealed to be a promising treatment for HLH $(10,32)$. Therapeutic IFN- $\gamma$ neutralization in an animal model of macrophage activation syndrome improved survival rate and body weight recovery and decreased downstream proinflammatory cytokine and chemokine levels, which suggested that this strategy can be used to control the cytokine storm in patients with HLH (33). In the present work, an imbalance between IFN- $\gamma$ and endogenous anti-IFN- $\gamma$ IgG Ab may have interfered with cytokine production, which induced an autoimmune response that contributed to HLH pathogenesis.

There were limitations in the present study. Firstly, the sample size was relatively small, as HLH is a rare hematological disease with an extremely low incidence rate; a larger panel of HLH samples would increase the statistical power of the analysis. Secondly, only a description of the clinical test results were provided, without extensive quantification. And finally, HLH diagnosis based on a single factor (IFN- $\gamma$ ) may not meet clinical needs. Therefore, future studies should investigate the feasibility of using the biochip for combined detection of multiplex HLH biomarkers, such as IL-10, IL1 $\beta$, IL-6, IL-8, TNF $\alpha$ and sCD25, in a larger panel of samples.

In conclusion, a PDITC-activated PAMAM modification strategy was developed to enhance the protein detection sensitivity and specificity of a gold biochip. The LOD of IFN- $\gamma$ in serum by the modified biochip was $50 \mathrm{pg} / \mathrm{ml}$. In addition, the biochip was able to simultaneously detect IFN- $\gamma$ and antihuman IFN- $\gamma$ IgG Ab in clinical samples from patients with HLH. The present results demonstrated that the PDITC-activated PAMAM-modified biochip may be a promising tool for the early and accurate diagnosis of HLH.

\section{Acknowledgements}

Not applicable.

\section{Funding}

The present study was in part supported by the Translational Medicine Research Program of Anhui Province of China (grant no. 2017zhyx37) and the National Natural Science Foundation of China (grant no. 81901238).

\section{Availability of data and materials}

The datasets used and/or analyzed during the current study are available from the corresponding author on reasonable request.

\section{Authors' contributions}

WDD, MES, YXD and LY designed the research. ZJS, LY, HL, SSL and JH performed the experiments and contributed to the data acquisition. ZJS, QL and SGL interpreted and analyzed the data. JH, YG, YXD and MES performed the sample collection and clinical tests. YXD, LY and ZJS drafted the manuscript, and LY, MES and WDD reviewed the manuscript. SSL and LY revised the manuscript critically for important intellectual content. All authors read and approved the final manuscript.

\section{Ethics approval and consent to participate}

The present study was approved by the Institutional Ethical Committee of Anhui Medical University. All procedures performed in studies involving human participants were in accordance with the ethical standards of the institutional and/or national research committee (include name of committee + reference number) and with the 1964 Helsinki declaration and its later amendments or comparable ethical standards. Written informed consent was provided by all individual participants included in the study.

\section{Patient consent for publication}

Not applicable.

\section{Competing interests}

The authors declare that they have no competing interests.

\section{References}

1. Gupta S and Weitzman S: Primary and secondary hemophagocytic lymphohistiocytosis: Clinical features, pathogenesis and therapy. Expert Rev Clin Immunol 6: 137-154, 2010.

2. Tang YM and Xu XJ: Advances in hemophagocytic lymphohistiocytosis: Pathogenesis, early diagnosis/differential diagnosis, and treatment. ScientificWorldJournal 11: 697-708, 2011.

3. Trottestam H, Horne A, Aricò M, Egeler RM, Filipovich AH, Gadner H, Imashuku S, Ladisch S, Webb D, Janka G, et al: Chemoimmunotherapy for hemophagocytic lymphohistiocytosis: Long-term results of the HLH-94 treatment protocol. Blood 118: 4577-4584, 2011

4. Henter JI, Horne A, Aricó M, Egeler RM, Filipovich AH, Imashuku S, Ladisch S, McClain K, Webb D, Winiarski J and Janka G: HLH-2004: Diagnostic and therapeutic guidelines for hemophagocytic lymphohistiocytosis. Pediatr Blood Cancer 48: 124-131, 2007.

5. Chandrakasan S and Filipovich AH: Hemophagocytic lymphohistiocytosis: Advances in pathophysiology, diagnosis, and treatment. J Pediatr 163: 1253-1259, 2013.

6. Xu XJ, Tang YM, Song H, Yang SL, Xu WQ, Zhao N, Shi SW, Shen HP, Mao JQ, Zhang LY and Pan BH: Diagnostic accuracy of a specific cytokine pattern in hemophagocytic lymphohistiocytosis in children. J Pediatr 160: 984-990.e1, 2012.

7. Tsuji T, Hirano T, Yamasaki $\mathrm{H}$, Tsuji $\mathrm{M}$ and Tsuda $\mathrm{H}$ : A high sIL-2R/ferritin ratio is a useful marker for the diagnosis of lymphoma-associated hemophagocytic syndrome. Ann Hematol 93: 821-826, 2014.

8. Allen CE, Yu X, Kozinetz CA and McClain KL: Highly elevated ferritin levels and the diagnosis of hemophagocytic lymphohistiocytosis. Pediatr Blood Cancer 50: 1227-1235, 2008.

9. Tang Y, Liao C, Xu X, Song H, Shi S, Yang S, Zhao F, Xu W, Chen X, Mao J, et al: Evaluation of Th1/Th2 cytokines as a rapid diagnostic tool for severe infection in paediatric haematology/oncology patients by the use of cytometric bead array technology. Clin Microbiol Infect 17: 1666-1673, 2011.

10. Jordan MB, Hildeman D, Kappler J and Marrack P: An animal model of hemophagocytic lymphohistiocytosis (HLH): CD8+ $\mathrm{T}$ cells and interferon gamma are essential for the disorder. Blood 104: 735-743, 2004.

11. Pachlopnik Schmid J, Ho CH, Chrétien F, Lefebvre JM, Pivert G, Kosco-Vilbois M, Ferlin W, Geissmann F, Fischer A and de Saint Basile G: Neutralization of IFNgamma defeats haemophagocytosis in LCMV-infected perforin- and Rab27a-deficient mice. EMBO Mol Med 1: 112-124, 2009.

12. Weidong D, Xueling M and Schneider EM: A direct immunoassay assessment of streptavidin- and N-hydroxysuccinimide-modified biochips in validation of serological TNFalpha responses in hemophagocytic lymphohistiocytosis. J Biomol Screen 13: 515-526, 2008. 
13. Liu Q, Liu SS, Li SG, Gao Y, Ye L, Johnson GOR, Song ZJ and Du WD: Establishment of a protein biochip to detect serum IgG antibodies against IL-2 and soluble CD25 in hemophagocytic lymphohistiocytosis. Clin Chim Acta 487: 256-263, 2018.

14. Dupuy AM, Lehmann S and Cristol JP: Protein biochip systems for the clinical laboratory. Clin Chem Lab Med 43: 1291-1302, 2005.

15. Moore CD, Ajala OZ and Zhu H: Applications in high-content functional protein microarrays. Curr Opin Chem Biol 30: 21-27, 2016.

16. Liu RH, Dill K, Fuji HS and McShea A: Integrated microfluidic biochips for DNA microarray analysis. Expert Rev Mol Diagn 6: 253-261, 2006

17. Campos BB, Oliva MM, Contreras-Cáceres R, RodriguezCastellón E, Jiménez-Jiménez J, da Silva JC and Algarra M: Carbon dots on based folic acid coated with PAMAM dendrimer as platform for Pt(IV) detection. J Colloid Interface Sci 465: 165-173, 2016.

18. Müller M, Agarwal N and Kim J: A cytochrome P450 3A4 biosensor based on generation 4.0 PAMAM dendrimers for the detection of caffeine. Biosensors 6: 44, 2016.

19. Jin H, Gui R, Gao X and Sun Y: An amplified label-free electrochemical aptasensor of $\gamma$-interferon based on target-induced DNA strand transform of hairpin-to-linear conformation enabling simultaneous capture of redox probe and target. Biosens Bioelectron 145: 111732, 2019.

20. Ma K, Zhang F, Sayyadi N, Chen W, Anwer AG, Care A, Xu B, Tian W, Goldys EM and Liu G: 'Turn-on' fluorescent aptasensor based on AIEgen labeling for the localization of IFN- $\gamma$ in live cells. ACS Sens 3: 320-326, 2018.

21. Pavlickova P, Jensen NM, Paul H, Schaeferling M, Giammasi C, Kruschina M, Du WD, Theisen M, Ibba M, Ortigao F and Kambhampati D: Antibody detection in human serum using a versatile protein chip platform constructed by applying nanoscale self-assembled architectures on gold. J Proteome Res 1: 227-231, 2002.

22. Chanphai P, Froehlich E, Mandeville JS and Tajmir-Riahi HA: Protein conjugation with PAMAM nanoparticles: Microscopic and thermodynamic analysis. Colloids Surf B Biointerfaces 150: 168-174, 2017.

23. Zhang $\mathrm{Y}$, Wang $\mathrm{F}$, Zhang $\mathrm{H}$, Wang $\mathrm{H}$ and Liu $\mathrm{Y}$ : Multivalency interface and $\mathrm{g}-\mathrm{C}_{3} \mathrm{~N}_{4}$ coated liquid metal nanoprobe signal amplification for sensitive electrogenerated chemiluminescence detection of exosomes and their surface proteins. Anal Chem 91: 12100-12107, 2019.
24. Zhang M, Ren Y, Wang Y, Wang R, Zhou Q, Peng Y, Li Q, Yu M and Jiang Y: Regulation of smooth muscle contractility by competing endogenous mRNAs in intracranial aneurysms. J Neuropathol Exp Neurol 74: 411-424, 2015.

25. Gandhiraman RP, Gubala V, Le NC, Volcke C, Doyle C, James B, Daniels S and Williams DE: Deposition of chemically reactive and repellent sites on biosensor chips for reduced non-specific binding. Colloids Surf B Biointerfaces 79: 270-275, 2010.

26. Ye L, Huang NL, Ma XL, Schneider M, Huang XJ and Du WD: Establishment of N-succinimidyl 4-(maleimidomethyl) cyclohexanecarboxylate (SMCC) modified biochip enabling concurrent detection of serum infectious antibodies in neuroborreliosis. Biosens Bioelectron 78: 404-410, 2016.

27. Otrock ZK, Hock KG, Riley SB, de Witte T, Eby CS and Scott MG: Elevated serum ferritin is not specific for hemophagocytic lymphohistiocytosis. Ann Hematol 96: 1667-1672, 2017.

28. Kurzrock R, Rohde MF, Quesada JR, Gianturco SH, Bradley WA, Sherwin SA and Gutterman JU: Recombinant gamma interferon induces hypertriglyceridemia and inhibits post-heparin lipase activity in cancer patients. J Exp Med 164: 1093-1101, 1986.

29. Lin A, Ma TP, Cheng FW and Ng PC: Neonatal haemophagocytic lymphohistiocytosis associated with maternal adult-onset still's disease. Neonatology 110: 267-269, 2016.

30. Oaks M, Taylor S and Shaffer J: Autoantibodies targeting tumor-associated antigens in metastatic cancer: Sialylated IgGs as candidate anti-inflammatory antibodies. Oncoimmunology 2 : e24841, 2013

31. Lovisari F, Terzi V, Lippi MG, Brioschi PR and Fumagalli R: Hemophagocytic lymphohistiocytosis complicated by multiorgan failure: A case report. Medicine (Baltimore) 96: e9198, 2017.

32. Avau A and Matthys P: Therapeutic potential of interferon- $\gamma$ and its antagonists in autoinflammation: Lessons from murine models of systemic juvenile idiopathic arthritis and macrophage activation syndrome. Pharmaceuticals (Basel) 8: 793-815, 2015.

33. Prencipe G, Caiello I, Pascarella A, Grom AA, Bracaglia C, Chatel L, Ferlin WG, Marasco E, Strippoli R, de Min C and De Benedetti F: Neutralization of IFN- $\gamma$ reverts clinical and laboratory features in a mouse model of macrophage activation syndrome. J Allergy Clin Immunol 141: 1439-1449, 2018.

This work is licensed under a Creative Commons Attribution-NonCommercial-NoDerivatives 4.0 International (CC BY-NC-ND 4.0) License. 